\title{
AiMT
}

Advances in Military Technology

Vol. 12, No. 1 (2017), pp. 147-161

ISSN 1802-2308, eISSN 2533-4123

DOI 10.3849/aimt.01179

\section{Using Aviation Simulation Technologies for Pilot Modelling and Flight Training Assessment}

\author{
$\mathrm{J}_{\text {Boril }}{ }^{1 *}, \mathrm{M} . \mathrm{Jirgl}^{2}$ and R. Jalovecky ${ }^{3}$ \\ ${ }^{1}$ Department of Air Force and Aircraft Technology, University of Defence, Czech Republic \\ ${ }^{2}$ Department of Control and Instrumentation, Brno University of Technology, Czech Republic \\ ${ }^{3}$ Department of Aircraft Electrical Systems, University of Defence, Czech Republic
}

The manuscript was received on 6 March 2017 and was accepted after revision for publication on 23 June 2017.

\begin{abstract}
:
This paper summarises many years of the results of the development and modelling of human behaviour while flying an aircraft, from a flight automation point of view. The introduction presents the challenges of describing and modelling human behaviour. Based on that knowledge, options for acquiring parameters for a pilot behaviour model are described. Then, analysis of pilot response is presented, acquired from many tests on two simulators (stationary and motion-platform). These experimental tests are pilot responses to a visual stimulus and also partially to motion stimulus - step change in flight altitude where the task of the pilot is to return the flight, as quickly as possible to the original flight altitude. Due to the vast amount of test data files - missions from each test - the authors rewrote the identification algorithms for batch data processing and utilised a Salamon supercomputer located at Technical University of Ostrava. In the first phase of implementation of the identification algorithms, the calculations were 4 times faster, and after rewriting the algorithms for parallel calculations, the authors expect the speed to increase more than 10 times.
\end{abstract}

\section{Keywords:}

flight simulators, simulation technologies, pilot training, pilot modelling, human behaviour model, MATLAB ${ }^{\circledR}$

\section{Introduction}

Simulation technologies and training on simulators are spreading across the world. Natural infiltration of simulation technologies into a wide range of scientific fields and

\footnotetext{
* Corresponding author: Department of Air Force and Aircraft Technology, Faculty of Military Technology, University of Defence, Kounicova 65, 61200 Brno, Czech Republic.

Phone:+420 9734439 49, E-mail: jan.boril@unob.cz
} 
activities is fanned by rapid IT development and the increasing availability and affordability of technological gadgets.

Modern simulation technologies used for flight simulators and for modelling realistic combat situations are utilised in NATO to increase their military staff training quality, productivity and effectivity. These simulation technologies also support their mutual interoperability during command and operations, by creating conditions for quality military staff preparation; in this case, the preparation of aviation staff. Different combat flight simulators reproduce different reality elements to certain extent; however, their psychosomatic perception in reality is quite different. Generally, the model situations provided by quality simulators are, in principle, the same.

An advantage of flight simulators is the authenticity of the simulation, where the pilot feels as if he were sitting in a real aircraft. This feeling is, among others, enhanced by the simulator cockpit layout, including controls layout, signal controls layout, mathematical aircraft model and controls feedback force to the pilot, being identical to the real aircraft's layout and controls. Pilot training on flight simulators is much more cost effective than training in a real aircraft.

Another advantage of simulation technologies is not only the training cost reduction, but also the increase in flight safety. By using flight simulators, aircraft type re-training and emergency situations practice is also faster and done to a much higher quality, as these situations cannot be practiced in real aircraft - for safety and organisational reasons. In addition, training on flight simulators is not dependent on weather conditions, atmospheric conditions, operating status of the aircraft, the airport or the pilot's training level [1].

With the increased use of simulator technologies in training, it is, however, important to keep in mind that simulation can never fully replace real flight training, as it brings a false feeling of safety and dampens self-preservation instincts. International armies suggest, from experience, an optimal ratio of simulation to real practice of 3:7. The use of simulators provides a uniformed system of preparation of aviation staff and it enables the acquisition of ingrained and stable flying habits as well as the refreshing of existing knowledge. It also uniforms routine procedures enabling various solutions to random or standard situations [2].

The authors of this paper bring an approach to assessment of pilot training on flight simulators by mathematical modelling - using mathematical models of pilot behaviour. In principle, it consists of testing the pilot's ability to deal with an unpredicted situation during simulated flight on the simulator. By monitoring the control stick movements and the aircraft movement, it is possible to define input and output parameters for the consequent identification of transfer functions for a pilot behaviour model. From the transfer function parameters, and depending on the amount of pilots tested, practical time constant limits of the pilot behaviour model were calculated representing the training levels of the pilots. Research into this topic is also supported by the Czech Republic Technological Agency Project and 2 doctoral theses were created during this research $[3,4]$, describing this topic in detail.

\section{Human Behaviour Modelling}

In order to describe and analyse human behaviour, a suitable model must be used. Many researchers from various scientific fields have already tried to describe and model human behaviour. The majority of this research is, however, focused on neuro- 
science and psychology. Models created in this research area are mainly descriptive $[1,5]$.

Research conducted during past years, especially research of human behaviour done by professor D. T. McRuer, showed that after accepting certain simplifications, human behaviour (his dynamic properties) can be described using the theory of dynamic systems [6].

The main idea lies in the description of the Man-Machine System interaction [7] as a control loop, where the human serves as a human regulator, see Fig 1.

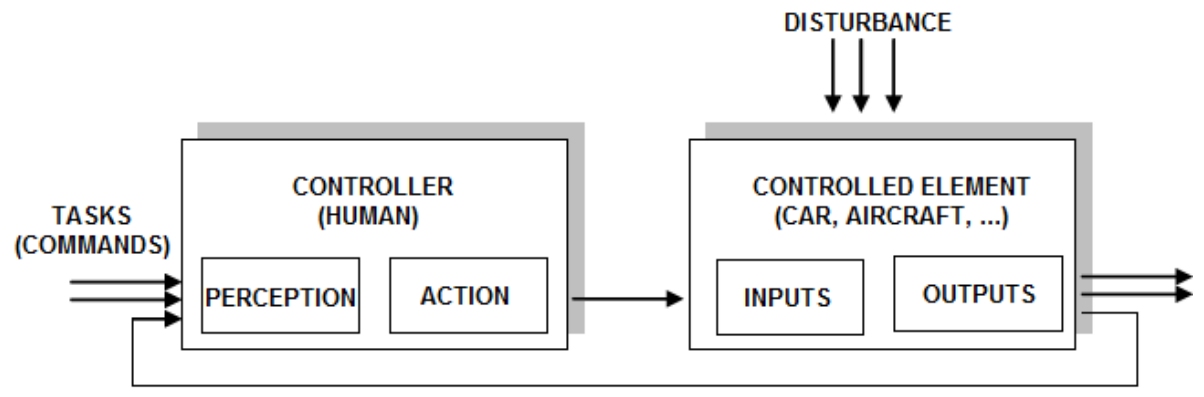

Fig. 1 Man-Machine System as a Control Loop

The human regulator is a very universal and effective regulator, as it can swiftly solve unexpected and unprecedented situation and it can adapt to various dynamic changes and condition changes as well. This type of adaptation was recently described by McRuer as a Crossover Law. This law describes the theory that the human adapts his interventions to the dynamics of the regulated system so that he can stabilise the whole system and so that the whole resultant system frequency characteristic, around its crossover frequency $\omega_{c}$, is an open regulation loop $F_{0}(\mathrm{j} \omega)$ with integration character, see (1) [8].

$$
F_{0}(\mathrm{j} \omega)=F_{R}(\mathrm{j} \omega) F_{S}(\mathrm{j} \omega)=\frac{\omega_{c}}{\mathrm{j} \omega} \mathrm{e}^{-\mathrm{j} \omega \tau},
$$

where $F_{R}(\mathrm{j} \omega)$ - frequency transfer of the regulator (human/pilot),

$F_{S}(\mathrm{j} \omega)$ - frequency transfer of the regulated system,

$\omega$ - angular frequency [rad/s],

$\mathrm{j}$ - imaginary unit,

$\omega_{c}-$ crossover frequency $[\mathrm{rad} / \mathrm{s}]$,

$\tau$ - transport (reaction) delay [s].

Recent research has shown that human behaviour models calculated by equation (1) are true only around the crossover frequency. In the case of considering a wider frequency range, it is necessary to alter, or generalize, these models. Based on tests in a wider frequency range, it was discovered that behaviour of a human regulator cannot be described only as a pure integrator - as it shows so-called quasi-integration character. A similar situation also applies to pure derivation. Based on this knowledge, general models were created, out of which the following formula (2) is the most used $[6,9]$.

$$
F_{(s)}=K \frac{\left(T_{3} \mathrm{~s}+1\right)}{\left(T_{1} \mathrm{~s}+1\right)\left(T_{2} \mathrm{~s}+1\right)} \mathrm{e}^{-\tau s},
$$


where $K$ - the human gain - increasing of force on the steers in relation to their deflection,

$T_{1}$ - the time constant characterizing dynamic properties of the human neuromuscular system (0.05 to $0.2 \mathrm{~s})$,

$T_{2}$ - the lag (integrating) time constant, i.e. human ability to realize varying activity $(0.2$ to $20 \mathrm{~s})$,

$T_{3}$ - the lead (derivative) time constant - it is related to human's ability of prediction ( 0.5 to $20 \mathrm{~s})$,

$\tau$ - the transport - reaction delay ( 0.2 to 1 s), i.e. time of human's response,

$\mathrm{s}$ - the Laplace operator.

This model is a general model used for a wide range of activities connected with machine or aircraft control. Its features and use are discussed and analysed for example in $[7,10]$. Based on real tests, it was proven that this model provides sufficiently accurate approximation of realistic human responses, see [11, 12]. Unlike other models presented in various publications, for example see $[13,14]$, this model is relatively easy to use and individual parameters can be clearly interpreted. These parameters are mainly within the known ranges and they characterise the ability (capability) of the human / pilot to adapt to the controlled dynamics of the system.

To find the exact parameter values, it is necessary to perform many pilot response tests - response to defined movement of an aircraft, and then to subject the acquired results to a suitable mathematical process - identification. One of the identification methods uses, for example, an identification algorithm based on minimization criteria of the sum of squared deviations, according to (3).

$$
\text { KRIT }=\sum_{i=1}^{n}\left(y(i)-y_{m}(i)\right)^{2},
$$

where $y$ - the real (measured) output value,

$y_{\mathrm{m}}-$ the modelled (estimated) output value,

$n$ - the amount of data.

After testing a sufficient number of pilots for the same flight situation, the acquired coefficients, if possible, could be used for the pre-set simulation schematics.

It is not possible to perform a sufficient number of tests during real flights, as it is technically and financially demanding. That is why pilot response tests, within a defined flight section, are performed in flight simulators. These simulators are ideal for simulating many "standard" flight situations that can be repeated many times with the same initial conditions. This way many pilot's behaviour/interventions during the flight can be measured and also the training level of particular pilots can be gradually assessed during their training.

\section{Flight Simulator Used for Testing Pilots}

For testing pilots, it was important to use flight simulators that could record not only flight parameters, but also information about elevator deflections, engine thrust and pedal movements - at a sufficient recording frequency. If a pilot reaction delay $\tau$ (that is between 0.2 to $1 \mathrm{~s}$ ) needs to be assessed, then the recording frequency should be minimum $20 \mathrm{~Hz}$. For testing and research purposes, it is necessary to have a test device with the option to interfere with the flight during the simulation and to change some flight conditions and parameters. 
For testing pilot responses, a flight simulator was built at Brno University of Defence, running X-Plane 10 Pro software. It consists of two work stations - a pilot station (the tested person) and an instructor station (PC operator). Both stations are connected via intranet to share data. The Pilot Station (see Fig.2) consists of a control PC, 5 widescreen monitors for displaying flight situations and one touch screen for simulation of instrument panel controls. The simulator also consists of mechanical controls for the pilot - pedals and a joystick (interchangeable for a yoke) for flight control. Other controllers are for landing gear manipulation, engine thrust control, flaps control, etc., managing flight speed, flight mode, take-off and landing. The Instructor Station is much simpler. It consists of a control PC and one screen. The instructor watches the flight situation and controls the tested pilot by instructions or by changing flight parameters.

This experimental site with flight simulator is mainly used for research purposes. A secondary purpose of this simulator is for student-pilots to prepare for flights and get familiar with flight habits and procedures.

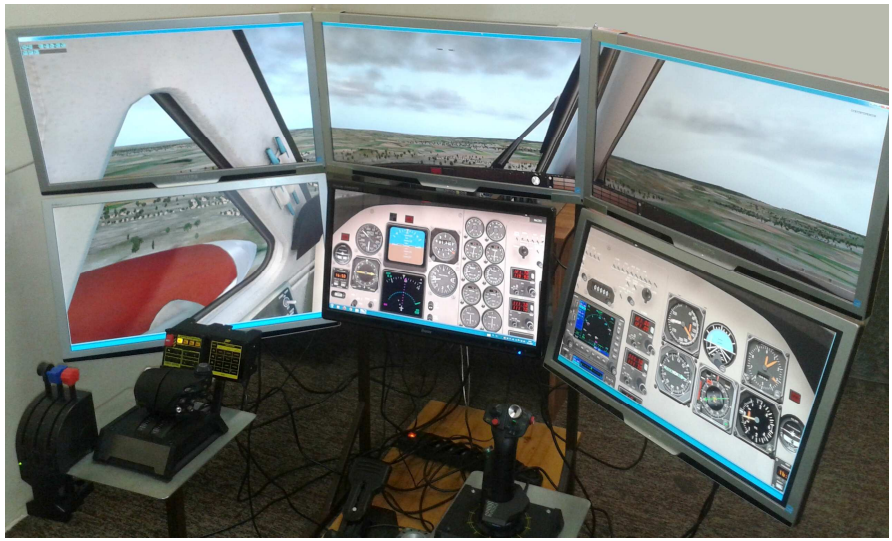

Fig. 2 Flight simulator for testing human factor, located at Department of Aircraft Electrical Systems at University of Defence

\section{Options of Mathematical Analysis for Human Behaviour while Flying an Aircraft}

The mind map in Fig. 3 clearly shows the scale of analysis for human behaviour while flying an aircraft. The outputs from the flight simulator are missions that represent a certain part of one test for a specific pilot. Before the actual analysis, it is possible to select the analysis method and the pilot behaviour method. The model is selected according to the basic equation (2) - pilot model Type "A" or its simplified versions (pilot model type "B" and "C") or extended versions (pilot model type "D" up to "F"). After the analysis, the results are time constants, transport delay or gain - model amplification, statistical data and graphs - providing a clear summary of the results. The graphs are identification flows, root distribution (so called characteristic equations), and transfer function of the pilot behaviour model.

Mathematical analysis of pilot behaviour based on the above approach is described in doctoral theses [3] and [4]. Some results from these theses are provided in the following chapters. 


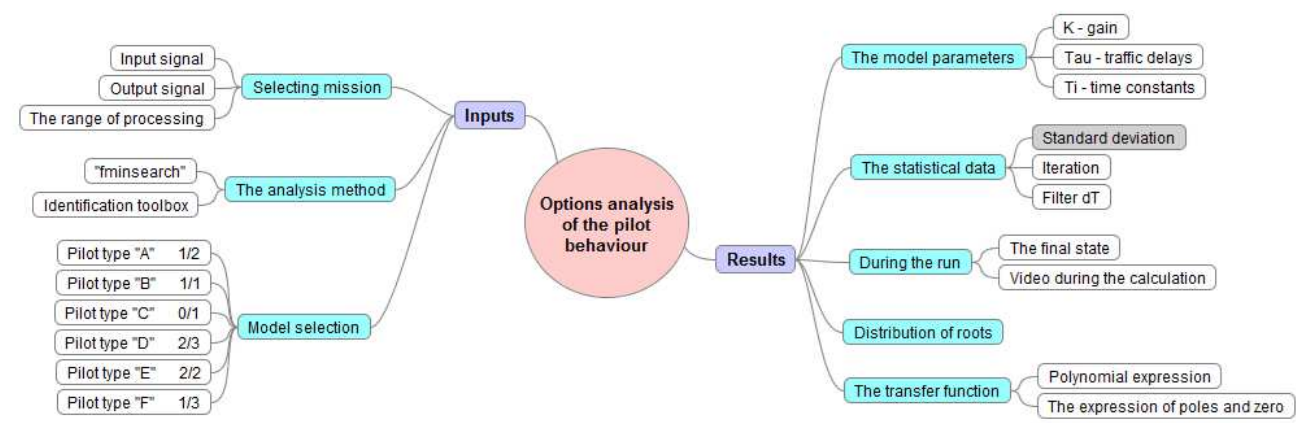

Fig. 3 Options of Mathematical Analysis for Human Behaviour

\section{Testing Pilots with Different Flying Experience}

In Doctoral Thesis [3], the author was studying how to determine time constant ranges for transfer functions of human behaviour. A flight simulator was used for these tests, see Fig. 2. Twenty-nine tests were performed with eleven pilots of various experience levels. These tests were divided into groups according to the pilots' flying experience level.

\subsection{Pilots without Previous Experience}

The tested subjects were 4 student pilots from the University of Defence, studying in the field of aviation. First, the students were introduced to the aircraft controls, to the instruments in the cockpit and mainly to the method of controlling the aircraft. Then they performed test flights to get familiar with basic flying skills. Afterwards the students practiced preparing for landing, straight flight, etc. Finally their flight was recorded to the instructor's station.

Fig. 4 shows a typical graph for pilots of this category. They found it difficult to move the joystick gradually as in the graph there are many overshoots with high amplitude around the required altitude. Their flying inexperience is clearly visible here. From all the tests with this pilot group, using identification algorithms according to equations (2) and (3), transfer function parameters were determined for pilot behaviour without any previous flying experience.

In most cases, the students could stabilize the aircraft after some time, but the time taken, the number of overshoots and their amplitudes made the difference between experienced and inexperienced pilots. This statement is also supported by time constants of the transfer functions for the pilot behaviour models.

\subsection{Pilot Experienced in Flying on Flight Simulators and in Gliding}

The second group of pilots tested on flight simulators were two pilots with limited flying experience. The first pilot had experience on flight simulators - Microsoft Flight Simulator software. The second pilot had experience with glider aircraft. These two pilots did not need any initial training for aircraft controls, instrument panels in cockpit, etc. Before the tests, they were given sufficient time to warm up for flying.

Fig. 5 shows one way of dealing with a sudden change of flight altitude. The pilot moved the control stick quite steadily into a position where the aircraft started descending. Then, he started to "fine tune" the altitude. Around the desired altitude, 
a slight overshoot took place due to the momentum of the aircraft. This action can be credited to the pilot's experience with this particular aircraft type and also to the amount of pilot flight hours. The pilot applied pressure to the elevators evenly and thus there were no fast control stick movements - black line.

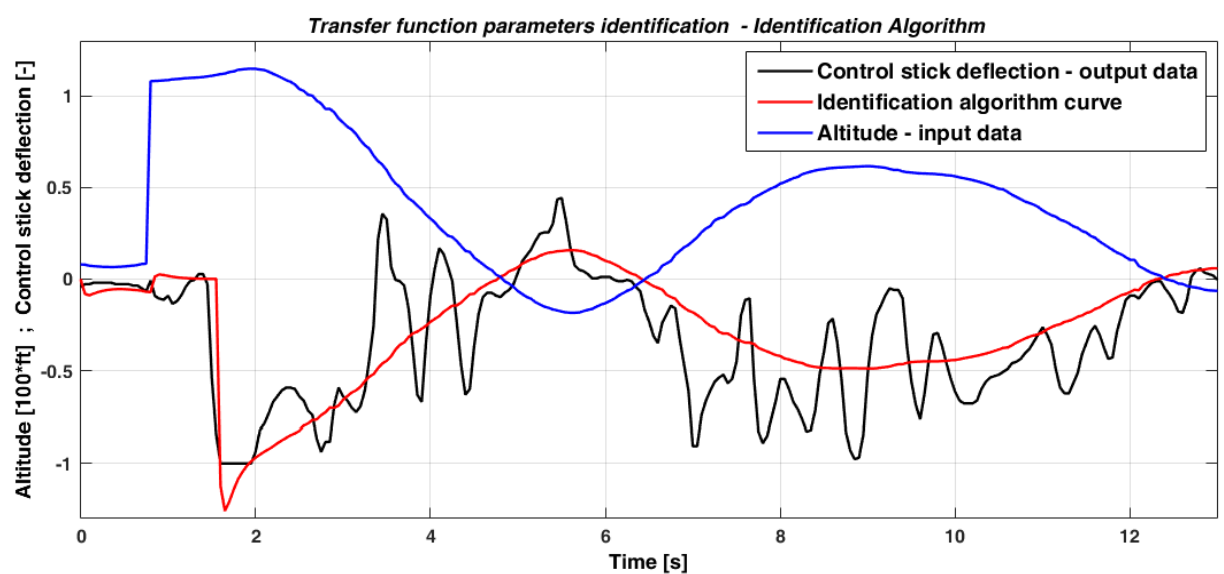

Parameter ranges of transfer function (2):

- $T_{1}=0.01 \div 0.09[\mathrm{~s}]$,

$$
T_{2}=0.17 \div 2.81[\mathrm{~s}]
$$$$
T_{3}=0.30 \div 3.99[\mathrm{~s}]
$$

- $\tau=0.40 \div 0.75[\mathrm{~s}]$,

$$
|K|=1.27 \div 1.76[-] \text {, }
$$$$
\sigma=0.12 \div 0.30[-] \text {. }
$$

Fig. 4 Example of identification of pilot without previous flying experience (Pilot 6 - test No. 9) and acquired ranges of individual parameters

In this test, 2 peaks are sticking out (minimum and maximum) neuromuscular Time Constants $T_{1}$. In both cases, the neuromuscular time constant is most likely influenced by the created non-linearities. When the maximum deflection of the yoke is reached, the algorithm cannot follow the curve's trend.

\subsection{Pilots with Practical Experience on Z-142CAF}

The most tests were conducted with student pilots specialising in becoming military aircraft pilots. The amount of tests with these pilots is exactly half of the total amount of tests conducted.

Fig. 6 is compiled from more than three hundred iterations, and shows an exact descent to the flight altitude, without extra overshoots. Within six seconds, the pilot brought the aircraft back to a straight horizontal flight. Parameters of the transfer function for the pilot behaviour model lay below average values. Mean-root-square error, determining the accuracy of the interpolated output curve from the control stick movement, is just above 0.1. Such an error is considered good when using flight simulators and the transfer function is calculated from equation (2). Individual parameters of the transfer function for pilot behaviour have different values for each test. From the total of sixteen tests, a minimum and maximum value was selected as they set the limits of time constants, gain and mean-root-square. After the tests with the student military aircraft pilots, parameter ranges of transfer function for a pilot behaviour model were determined. Ranges are shown below. 


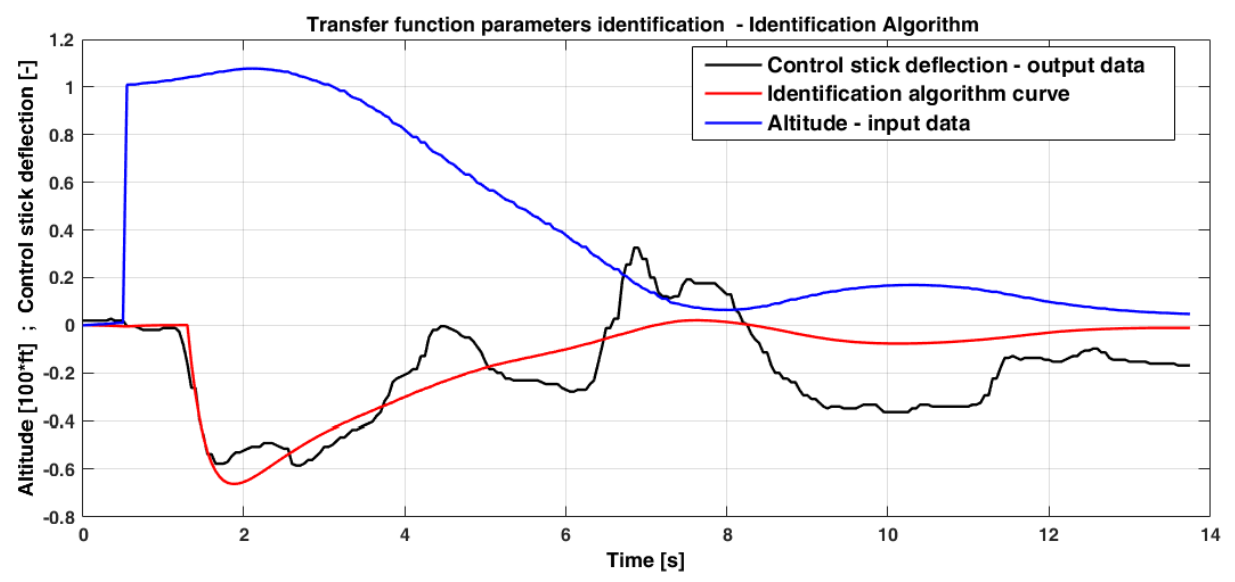

Parameter ranges of transfer function (2):

$$
\begin{aligned}
& \text { - } T_{1}=0.01 \div 0.43[\mathrm{~s}], \quad T_{2}=0.44 \div 2.32[\mathrm{~s}], \quad T_{3}=1.12 \div 6.61[\mathrm{~s}], \\
& \text { - } \tau=0.32 \div 1.00[\mathrm{~s}], \quad|K|=2.46 \div 5.64[-], \quad \sigma=0.10 \div 0.32[-] \text {. }
\end{aligned}
$$

Fig. 5 Example of pilot identification, pilot with experience on flight simulators (Pilot 8 - Test No. 14) and acquired ranges of individual parameters

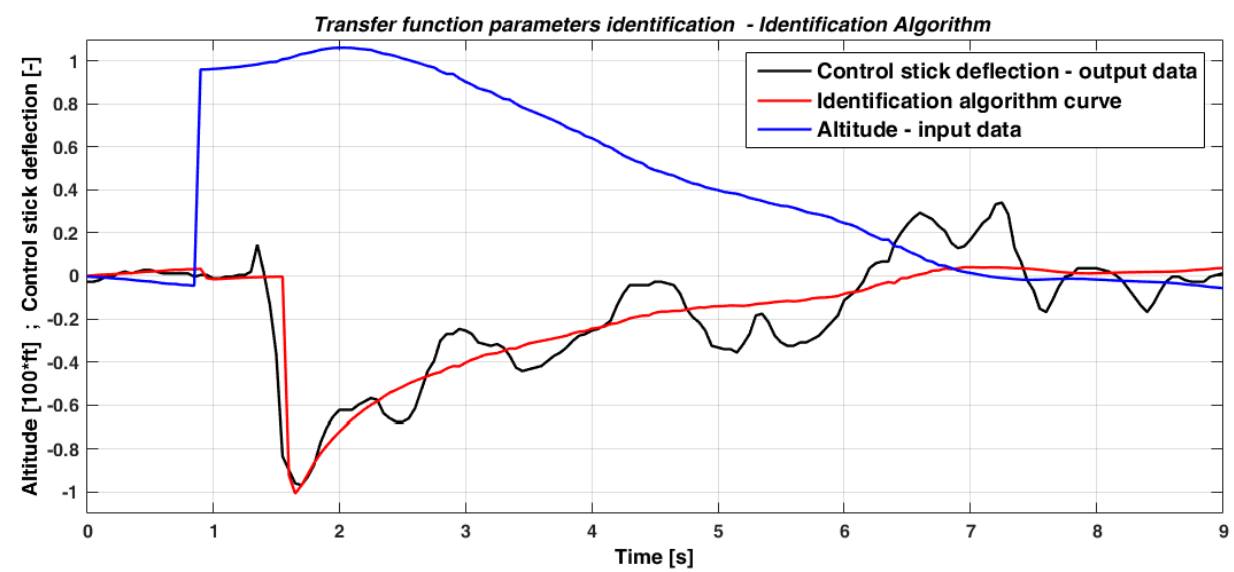

Parameter ranges of transfer function (2):

$$
\begin{aligned}
& \text { - } \mathrm{T}_{1}=0.01 \div 0.2[\mathrm{~s}], \quad \mathrm{T}_{2}=0.28 \div 1.9[\mathrm{~s}], \quad \mathrm{T}_{3}=0.33 \div 4.14[\mathrm{~s}], \\
& \text { - } \tau=0.38 \div 0.63[\mathrm{~s}], \quad|K|=0.73 \div 9.20[-], \quad \sigma=0.10 \div 0.27[-] \text {. }
\end{aligned}
$$

Fig. 6 Example of pilot identification, pilot with practical experience (Pilot 10 - Test No. 23) and acquired ranges of individual parameters

It is not possible to say that pilots with practical experience always reached better results than pilots from other categories. In this phase of testing, the experienced pilots also tried different strategies of returning the aircraft back to the desired flight altitude. Within these long-term tests (see next chapter), the parameter ranges of the transfer function were becoming better due to the acquired experience, stereotypes and familiarisation to the routine processes. 


\section{Pilot Training Level Assessment}

Doctoral thesis [4] follows up an earlier study [3] and based on new information it focuses on the development and usage of pilot behaviour mathematical models for assessing their actual current status - training level.

One way of objectively assessing a pilot's training level is to assess pilot response based on practical tests. The basic principal of these tests is repeated tests of pilot response to a visual stimulus. Visual stimulus in this case is a step change of flight altitude, identified by an altimeter. For testing purposes, a dual engine propeller King Air C90B aircraft was selected with one defined standard situation - horizontal stable flight at an altitude of $2900 \mathrm{ft}$, with a speed of $170 \mathrm{mph}$. After a certain period of time, a drop in flight altitude occurred and the task of the pilot was to return to the original altitude as quickly and accurately as possible. A detailed description of this experiment is, for example, in [15].

In doctoral thesis [4], two independent sets of tests were analysed, using eight pilots and ten missions. The tested pilots were $4^{\text {th }}$ year bachelor degree students at the Air Force and Aircraft Technology Department that had flown (in the time of the $1^{\text {st }}$ set of tests) about 60 flight hours. Then they underwent mandatory training during which they flew additional 20 flight hours. After this mandatory training, the $2^{\text {nd }}$ set of tests took place. Both sets of tests were conducted under the same conditions, on the same type of simulator - the stationary simulator at Brno University of Defence. The data results of these tests were processed and analysed by different methods.

\subsection{Method Based on Modelling Human Behaviour}

One of these methods is based on assessment of changes in dynamic behaviour during time, in other words, in different phases of the training. This method is using identified parameters of the pilot behaviour model, see (2). Individual parameters of this model, especially $T_{2}, T_{3}$, and $\tau$, represent the current pilot status, from his dynamic properties point of view, corresponding to his approach and style of flying. The ratio of time (regulating) constants $T_{2}$ and $T_{3}$ represents the character of the pilot's intervention slow and dampened if $T_{2}>T_{3}$ or fast (of a derivation character) if $T_{2}<T_{3}$. Transport (or reaction) delay of the pilot $\tau$ is represented by visual information processing time and the time taken for corresponding counter action. In other words, this delay corresponds to the pilot's ability and speed to react to the changed situation.

The provided parameters were identified from the tested responses for both sets of tests, individual pilots and missions. Eight pilots took part in the $1^{\text {st }}$ set of tests, each of them did ten repeated test missions. Only seven pilots took part in the $2^{\text {nd }}$ set of tests and each of them did ten missions. To make the sets of tests comparable, the pilot that did not take part in the $2^{\text {nd }}$ set of tests, was not considered at all.

The identified parameters for the individual pilots and missions can be taken as statistical data files and their basic characteristics can be determined. One option for determining their characteristics is depiction of so called "Box Plot Graph" for the individual parameters and the individual sets of tests, see Fig. 7.

The provided Box Plot Graphs show division of the individual parameters for the individual sets of tests. The area marked by the black segmented line represents the range of the parameter at the importance level of $5 \%$. The blue border line defines the lower and upper quartiles, i.e. contains the upper $50 \%$ of the data from the file. The red line in the blue box represents the median. Red crosses represent so-called remote values. 


\section{The first testing set}
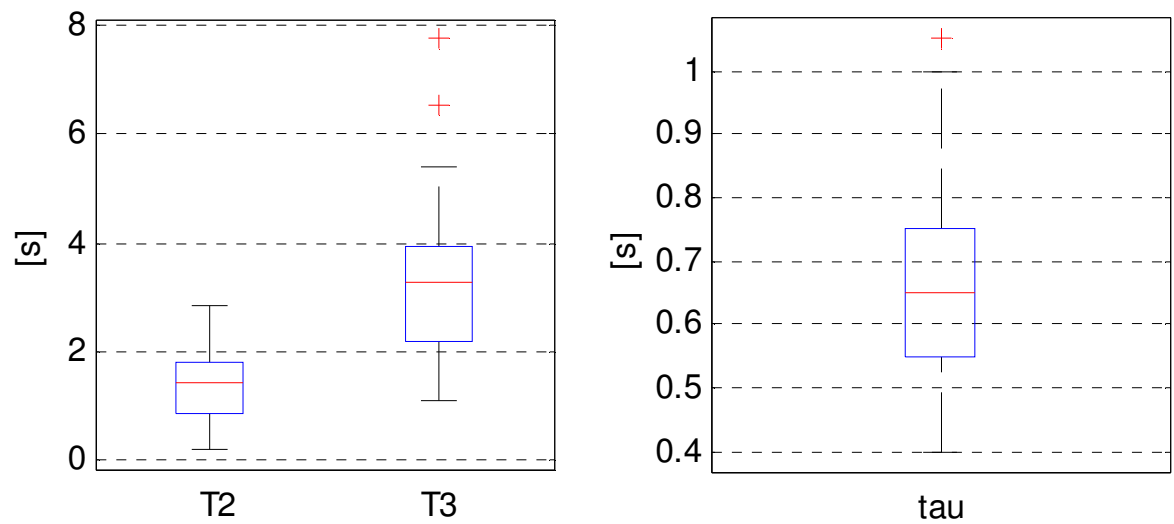

The second testing set
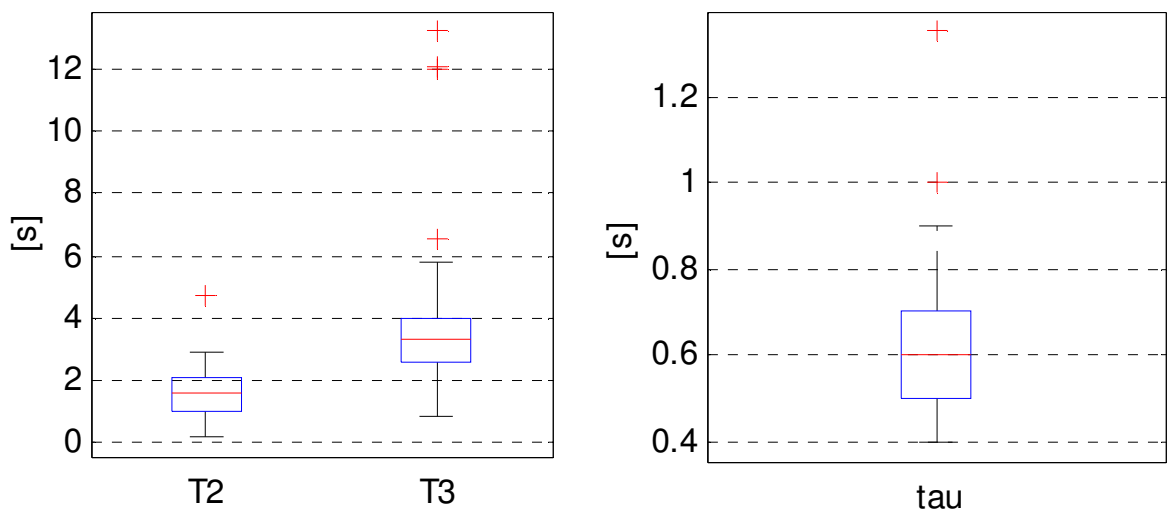

Fig. 7 Box Plot Graphs for selected model 2 parameters for a) $1^{s t}$, b) $2^{\text {nd }}$ set of tests.

Ranges of these parameters, especially the values located in the area between the upper and the lower quartile, correspond to the ranges published in $[3,7]$ and are very close to the intervals presented in Chapter 5.3. These ranges correspond to the category of pilots with practical flying experience (in particular, experience with Z-142CAF). Correspondingly, pilots of these tests were pilots with practical flying experience. This proves that if a sufficient amount of tests were performed and results compared, the pilots could be categorised, providing assessment of the pilots' abilities based on their training level and experience.

To assess and compare individual pilot's abilities, average values of the pilot parameters were used in the following text; see Tab. 1 which clearly shows that average values of the neuromuscular time constants $T_{1}$ stay virtually the same for all repeated tests. This demonstrated that their value is characteristic for all pilots and is not dependant on their training level.

Pilot reaction time (transport delay) $\tau$ reduced for all pilots (in some cases it reduced dramatically, see Pilot 1 and Pilot 5). An exception was Pilot 4 whose reaction time increased by $0.1 \mathrm{~s}$. Gain $K$ and the regulation constants $T_{2}$ a $T_{3}$ representing the pilot's ability to adapt to the controlled dynamics and the speed of the pilot's response in most cases changed too. 
Tab. 1 Parameters of average pilot behaviour model for individual sets of tests $\left(A-1^{\text {st }}\right.$ set of tests, $B-2^{\text {nd }}$ set of tests)

\begin{tabular}{|l|c|c|c|c|c|c|c|c|c|c|}
\hline & \multicolumn{2}{|c|}{$\boldsymbol{K} \times \mathbf{1 0}^{-\mathbf{4}}[-]$} & \multicolumn{2}{c|}{$\boldsymbol{T}_{\mathbf{1}}[\mathbf{s}]$} & \multicolumn{2}{c|}{$\boldsymbol{T}_{\mathbf{2}}[\mathbf{s}]$} & \multicolumn{2}{c|}{$\boldsymbol{T}_{\mathbf{3}}[\mathbf{s}]$} & \multicolumn{2}{c|}{$\boldsymbol{\tau}[\mathbf{s}]$} \\
\cline { 2 - 12 } & $\mathbf{A}$ & $\mathbf{B}$ & $\mathbf{A}$ & $\mathbf{B}$ & $\mathbf{A}$ & $\mathbf{B}$ & $\mathbf{A}$ & $\mathbf{B}$ & $\mathbf{A}$ & $\mathbf{B}$ \\
\hline Pilot no.1 & 6.87 & 8.18 & 0.13 & 0.13 & 0.25 & 0.96 & 1.39 & 2.58 & 0.64 & 0.53 \\
\hline Pilot no.2 & 6.41 & 7.19 & 0.13 & 0.14 & 1.26 & 1.56 & 3.34 & 7.34 & 0.71 & 0.65 \\
\hline Pilot no.3 & 5.59 & 6.09 & 0.06 & 0.08 & 2.11 & 2.33 & 2.99 & 3.57 & 0.66 & 0.63 \\
\hline Pilot no.4 & 7.49 & 5.40 & 0.07 & 0.07 & 1.00 & 1.50 & 3.25 & 2.94 & 0.59 & 0.69 \\
\hline Pilot no.5 & 5.13 & 6.69 & 0.17 & 0.18 & 1.63 & 1.86 & 3.74 & 3.37 & 0.83 & 0.65 \\
\hline Pilot no.6 & 6.57 & 7.15 & 0.12 & 0.12 & 1.42 & 1.28 & 3.21 & 4.50 & 0.63 & 0.61 \\
\hline Pilot no.8 & 7.16 & 7.41 & 0.09 & 0.07 & 1.31 & 1.40 & 4.03 & 3.03 & 0.67 & 0.60 \\
\hline
\end{tabular}

\subsection{Method Based on Crossover Frequency}

This method uses equation (1), or in other words, it is based on a description of a regulation circuit made up of a regulator - the pilot $F_{\mathrm{R}}(\mathrm{j} \omega)$, a regulated system regulated element $F_{\mathrm{S}}(\mathrm{j} \omega)$, using frequency characteristics of an open regulation circuit $F_{0}(\mathrm{j} \omega)$.

Crossover frequency $\omega_{\mathrm{C}}$ is the point in the frequency characteristics in logarithmic coordinates where the amplitude-frequency characteristic crosses axis $0 \mathrm{~dB}$. It is connected to the dynamic properties of the regulation circuit. In this case, it is suitable to use this parameter, for example, to assess the speed of the previous action. High crossover frequency indicates a fast regulation process, i.e. the higher the crossover frequency $\omega_{\mathrm{C}}$, the faster the pilot can regulate or reach the desired level.

To be able to express the transfer of the open loop and depict its frequency characteristics (in logarithmic coordinates), it is first necessary to create (describe) the regulator model $F_{\mathrm{R}}(\mathrm{j} \omega)$ and the regulated system model $F_{\mathrm{S}}(\mathrm{j} \omega)$ for this situation.

As the aim of this assessment is to compare the abilities of the individual pilots, for this regulator model $F_{\mathrm{R}}(\mathrm{j} \omega)$, it is possible to use the equation (2) for creating (average) models of the individual pilots' behaviour, where the individual parameters $K, T_{1}, T_{2}, T_{3}$ and $\tau$ are shown in Tab. 1 .

The system model $F_{\mathrm{S}}(\mathrm{j} \omega)$ can be simply approximated around the crossover frequency area using a second order transfer function with a numerator polynomial containing an unstable root, the so-called unstable zero of the system. The model parameters were identified from the graphs using the MATLAB tool - System Identification Toolbox. This topic is described in detail, for example, in [16, 17]. The resultant system in operator form is as follows (4).

$$
F_{S}(s)=\frac{K_{n}\left(-T_{n} \mathrm{~s}+1\right)}{\left(T^{2} \mathrm{~s}^{2}+2 \xi T \mathrm{~s}+1\right)} \quad \rightarrow \quad F_{S}(s)=\frac{2.53 \times 10^{3}(-0.81 \mathrm{~s}+1)}{\left(62.35 \mathrm{~s}^{2}+8.01 \mathrm{~s}+1\right)},
$$

where $K_{n}-$ the system gain [-],

$T-$ the lag time constant [s],

$\xi$ - the system damping [-],

$T_{n}-$ the lead time constant $[\mathrm{s}]$. 


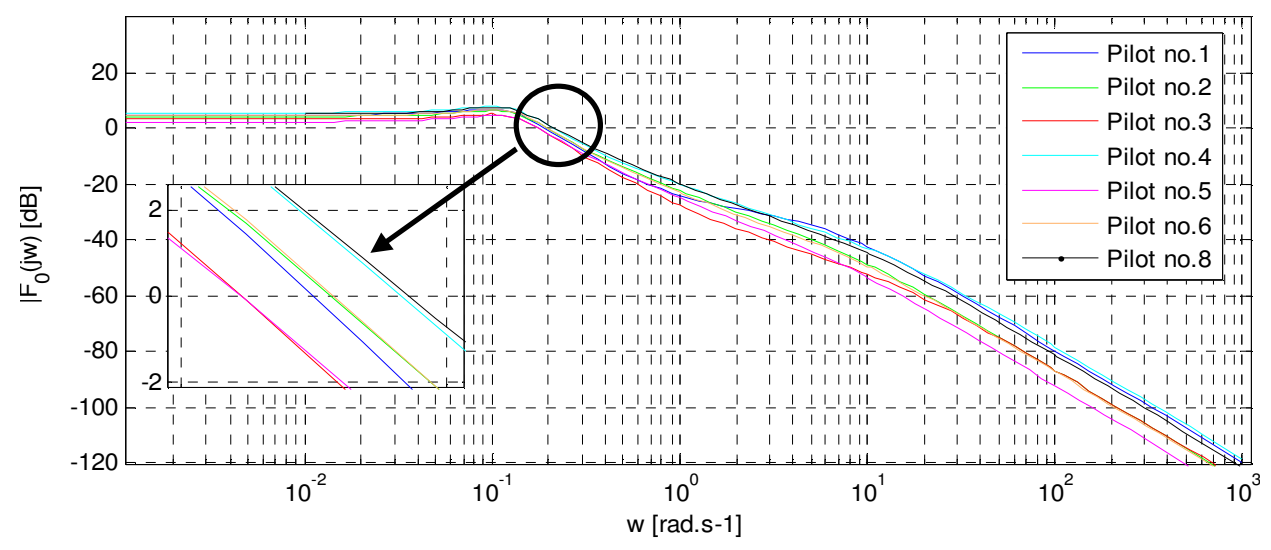

Fig. 8 Amplitude-frequency characteristics of an open regulation loop for individual pilot - the crossover frequency are marked for first sets of tests.

Amplitude-frequency characteristics of an open regulated loop $F_{0}(j \omega)$ in logarithmic coordinates can be depicted for individual cases (individual pilots) using the transfer functions $F_{R}(j \omega)$ and $F_{S}(j \omega)$, or $F_{R}(s)$ and $F_{S}(s)$. These characteristics are then used to determine the value (location) of the crossover frequency $\omega_{\mathrm{C}}$. See Figs. 8 and 9 for characteristics of individual pilots and individual sets of tests.

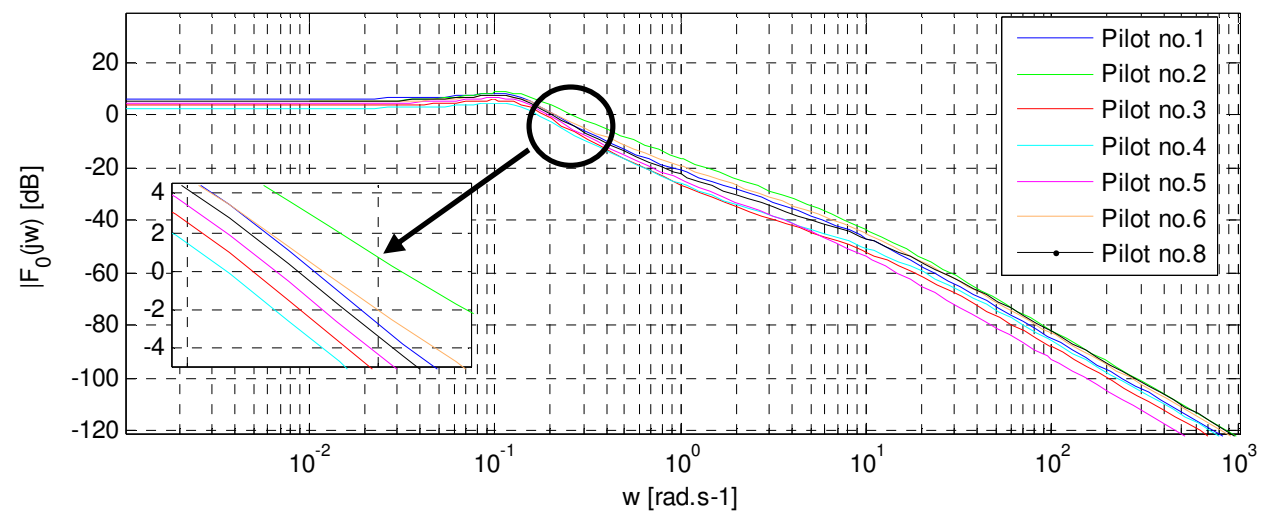

Fig. 9 Amplitude-frequency characteristics of open regulation loop for individual pilots - the crossover frequency is marked for second sets of tests.

Based on the crossover frequency of individual pilots and individual sets of tests, it is possible to assess the differences in average pilot regulation speed. Comparison of the calculated crossover frequencies $\omega_{\mathrm{C}}$ for individual pilots for $1^{\text {st }}$ and $2^{\text {nd }}$ set of tests is depicted in graph Fig. 10.

As mentioned above, the rule applies that the higher the crossover frequency $\omega_{\mathrm{C}}$, the faster the regulation. Results in Fig. 10 show that in the majority cases this frequency increased, except Pilot 4 (and also slightly Pilot 8). 


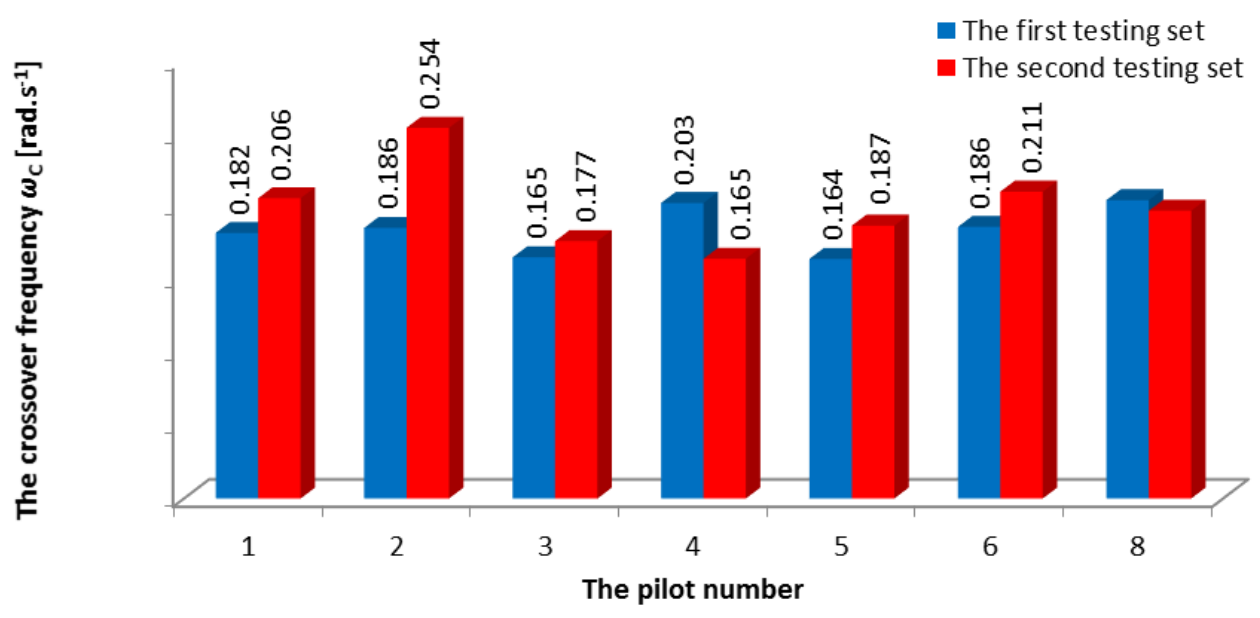

Fig. 10: Comparison of crossover frequencies for individual pilots and individual sets of tests

Fig. 11 also visually confirms these results, showing average flight altitudes based on control stick movements. The altitude was calculated as an average of the measured data for individual missions and individual pilots. The connection with crossover frequency was during the transition period - i.e. regulation speed (reaching the desired value). It is clear from these graphs that the differences between individual pilots are very prominent. The time for reaching the desired value $t w$ is in both cases within the interval from 9 to $20 \mathrm{~s}$. Nevertheless, a comparison of this time for each pilot in both test sets is important. Pilot 1 and Pilot 2 both improved significantly; on the contrary, Pilot 4 became worse, as his time nearly doubled.
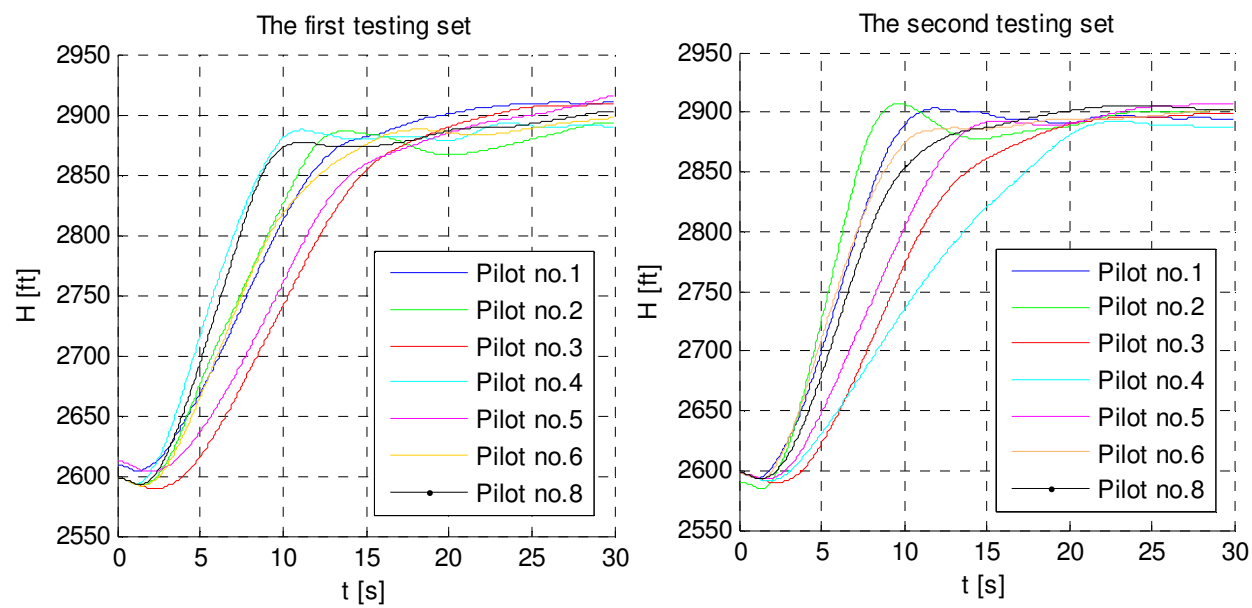

Fig. 11: Comparison of average responses to flight altitude $H$ based on individual pilot control movements $-1^{\text {st }}$ and $2^{\text {nd }}$ set of tests. 


\section{Conclusion}

After comparing the resultant transfer function parameter ranges listed next to the graphs Fig. 4 - Fig. 7, with theoretical ranges of time constants, it can be said that it is also possible to reach a realistic model of pilot behaviour via simulations. The authors are aware of the fact that one of the factors affecting the test results in Chapter 5 is pilot inexperience or for some pilots it is also the long-interval between flying practice on the simulator. This is also supported by test results showing that pilots shortened their time of bringing the aircraft back to steady and horizontal flight with repeated attempts. These results are being archived for the purpose of long-term comparison of changes of transfer function parameters for individual pilots - Chapter 6 .

The authors conducted many tests on flight simulators, acquiring the necessary data for parameter identification of transfer functions for a pilot behaviour model. If a sufficient amount of test data from a certain pilot is acquired on the flight simulator, it is possible to determine statistical development errors in the pilot's behaviour while flying an aircraft, to determine their training level, fatigue, lack of concentration, etc. Prediction of human behaviour while flying an aircraft is a must for a successful reduction in the undesired effects of human factors in air transport.

Further research in this field shall include more experimental tests with a large group of pilots, acquiring, analysing and comparing pilot's parameter changes over time and changes based on training level. Further investigations shall also include utilising more advanced models of human behaviour or utilising other types of simulators.

\section{Acknowledgement}

This paper was written within Technology Agency of the Czech Republic Project, No.TA04031376 research/Developing Methodology for Training of Aviation Specialists L410UVP E20 and grant No. FEKT-S-17-4234 „Industry 4.0 in automation and cybernetics" financially supported by the Internal science fund of Brno University of Technology.

The work presented in this paper was also supported by the Czech Republic Ministry of Defence - University of Defence Development Program "Research of sensor and control systems to achieve battlefield information superiority" and "Support for operations of the Czech Air Force in local conflicts".

\section{References}

[1] FOYLE, D.C., HOOEY, B.L. et. al. Human Performance Models of Pilot Behavior. In Proceedings of the Human Factors and Ergonomics Society Annual Meeting. 2005, vol. 49, p. 1109-1113.

[2] ALlERTON, D.J. The Impact of Flight Simulation in Aerospace. The Aeronautical Journal, vol. 114, no. 1162, p. 747-756, 2010.

[3] BORIL, J. Analysis of Pilot-Aircraft Mechatronic System in View of Automatic Control Systems (in Czech) [Doctoral Thesis]. Brno: University of Defence, 2013.

[4] JIRGL, M. Analysis of Pilot's Behaviour Models during Flight (in Czech), [Doctoral Thesis]. Brno: Brno University of Technology, 2016. 
[5] RASMUSSEN, J. Information Processing and Human-Machine Interaction: An Approach to Cognitive Engineering. New York: North-Holland: Elsevier Science, 1986.

[6] McRUER, D.T. and KRENDEL E.S. Mathematical Models of Human Pilot Behavior. London: AGARD AG-188, 1974.

[7] HAVlikOVA, M., BRADAC, Z., SEDIVA, S. and JIRGL, M. A man as the regulator. Advances in Electrical and Electronic Engineering, vol. 12, no. 5, p. 469-475, 2014.

[8] McRUER, D.T. and KRENDEL E.S. Human Pilot Dynamics in Compensatory systems. USA: Air Force Flight Dynamics Laboratory, Research and Technology Division, Air Force Systems Command, United States Air Force, 1965.

[9] LONE, M. and COOKE, A. Review of pilot models used in aircraft flight dynamics. Aerospace Science and Technology, vol. 34, no. 1, p. 55-74, 2014.

[10] SZABOLCI, R., Pilot in the Loop Problem and Its Solution. Technical Sciences and Applied Mathematics, vol. 1, p. 12-22, 2009.

[11] BORIL, J., JALOVECKY, R. and ALI, R. Human - Machine Interaction and Simulation Models Used in Aviation. In Mechatronika, $201215^{\text {th }}$ International Symposium, 2012, p. 1-4.

[12] JIRGL, M., HAVLIKOVA, M. and BRADAC, Z. The Dynamic Pilot Behavioral Models. Procedia Engineering, vol. 100, p. 1192-1197, 2015.

[13] LONE, M., RUSENO, N. and COOKE, A.K. Towards Understanding Effects of Non-linear Flight Control System Elements on Inexperienced Pilots. The Aeronautical Journal, vol. 116, no. 1185, p. 1201-1206, 2012.

[14] QINGLING, L., TAN, X. and LONE, M. Towards the Design of a Pilot-induced Oscillation Detection and Mitigation Scheme. In AIAA Atmospheric Flight Mechanics (AFM) Conference, 2013, no. 5, p. 1-19.

[15] JIRGL, M., JALOVECKY R. and BRADAC, Z. Models of Pilot Behavior and Their Use to Evaluate the State of Pilot Training. Journal of Electrical Engineering, vol. 67, no. 4, p. 267-272, 2016.

[16] JIRGL, M. and JALOVECKY, R. Modelling and Simulation of Longitudinal Flight. In Proceedings of the $16^{\text {th }}$ International Conference on Mechatronics Mechatronika 2014, 2014, p. 228-233.

[17] FOSSEN, T.I. Mathematical Models for Control of Aircraft and Satellites. $2^{\text {nd }}$ ed. Department of Engineering Cybernetics, NTNU, 2011. 